\title{
El uso del software en operaciones con números naturales como herramienta de facilitación para el proceso de enseñanza de las cuatro operaciones: adición, sustracción, multiplicación y división
}

\author{
Larisse Lorrane Monteiro Moraes ${ }^{1}$ \\ larissemoraes.12@gmail.com \\ https://orcid.org/0000-0002-6906-0381 \\ Bruno Sebastião Rodrigues da Costa ${ }^{1}$ \\ matbrunocosta@gmail.com \\ https://orcid.org/0000-0002-9050-6392 \\ Valdinei Gomes Melo ${ }^{1}$ \\ vgmelo2017@gmail.com \\ https://orcid.org/0000-0001-8058-1295 \\ Talita Carvalho Silva de Almeida ${ }^{2}$ \\ talita_almeida@yahoo.com.br \\ https://orcid.org/0000-0001-5206-4354 \\ ${ }^{1}$ Universidade do Estado do Pará (UEPA, Brasil) \\ ${ }^{2}$ Universidade Federal do Pará (UFPA, Brasil)
}

Recibido: 31/05/2020 Aceptado: 28/07/2020

\begin{abstract}
Resumen
En vista de los profundos cambios que la sociedad contemporánea ha experimentado a través de los avances en la informatización, el uso de las Tecnologías de la Información y la Comunicación (TIC) en la práctica docente es de gran importancia. En este sentido, el objetivo es ofrecer educación tecnológica en las clases de matemáticas, lo que significa crear conciencia en la construcción del conocimiento matemático, contribuyendo profesionalmente y socialmente a la formación de este individuo. Por lo tanto, esta investigación es un extracto de un trabajo de finalización del curso, realizado con estudiantes de sexto año de la escuela pública de Educación Primaria y Secundaria, cuyo objetivo es investigar el potencial del uso de una secuencia didáctica para enseñar las cuatro operaciones del conjunto de números naturales, utilizando la plataforma APP Inventor 2. Por lo tanto, la investigación se guió por los pasos descritos por Ingeniería didáctica, Almouloud y Silva (2012). Los resultados obtenidos muestran esta herramienta como una excelente alternativa de enseñanza, una vez que el aprendizaje de los estudiantes resultó satisfactorio de acuerdo con los criterios de evaluación adoptados, con lo cual, el proceso de enseñanza y aprendizaje mediante el uso de operaciones de software con números naturales se volvió motivador, dinámico y facilitador.
\end{abstract}

Palabras clave: Educación Matemática; Software; Cuatro operaciones con números naturales. 


\title{
O uso do software operações com números naturais como ferramenta facilitadora para o processo de ensino das quatro operações: adição, subtração, multiplicação e divisão
}

\begin{abstract}
Resumo
Perante as profundas transformações que a sociedade contemporânea vem sofrendo por meio dos avanços da informatização, é de grande importância o uso das Tecnologias de Informação e. Comunicação (TIC), na prática docente. Nesse sentido, é almejada nas aulas de matemática a oferta de uma educação tecnológica, que auxilie o processo de construção do conhecimento matemático, o que contribui para que desafios inerentes ao processo de ensino e aprendizagem sejam minimizados, ou mesmo superados. Dessa forma, esta pesquisa é um recorte de um Trabalho de Conclusão de Curso, realizado com alunos do sexto ano da escola estadual de Ensino Fundamental, cujo o objetivo foi investigar a potencialidade do uso de uma sequência didática para o ensino das quatro operações do conjunto dos números naturais, utilizando a plataforma do APP Inventor 2. Para tanto a pesquisa foi balizada nos passos, descrito pela Engenharia Didática, Almouloud e Silva (2012). Os resultados obtidos mostram essa ferramenta como uma alternativa de ensino, uma vez que a aprendizagem dos alunos se mostrou satisfatória, segundo os critérios de avaliação adotados. Nesse sentido, o processo de ensino e aprendizagem por meio do uso do software operações com números naturais se tornou, motivador, dinâmico e facilitador.
\end{abstract}

Palavras Chave: Educação Matemática; Software; Quatro Operações com Números Naturais.

\author{
The use of software operations with natural numbers as a \\ facilitating tool for the teaching process of the four operations: \\ addition, subtraction, multiplication and division
}

\begin{abstract}
In view of the profound transformations that contemporary society has been undergoing through the advances of informatization, the use of Information Technologies and. Communication (ICT) in teaching practice is of great importance. In this sense, it is sought in the mathematics classes the offer of a technological education, which assists the process of building mathematical knowledge, which contributes to the challenges inherent in the teaching and learning process are minimized, or even overcome. Thus, this research is a cut of a Course Completion Work, conducted with students of the sixth year of the State School of elementary school, whose objective was to investigate the potentiality of the use of a didactic sequence for teaching the four operations of the set of natural numbers, using the platform of the APP Inventor 2. For this purpose the research was marked in the steps, described by the Didactic Engineering, Almouloud e Silva (2012). The results obtained show this tool as an alternative teaching, once the students' learning proved satisfactory, according to the evaluation criteria adopted. In this sense, the process of teaching and learning through the use of software operations with natural numbers has become, motivating, dynamic and facilitator.
\end{abstract}

Word-key: Mathematics Education; Software; Four Operations with Natural Numbers. 


\section{Introdução}

O ensino de Matemática possui particularidades que devem ser exploradas de maneira mais ampla e possível. No entanto, seu ensino e aprendizagem tem preocupado professores e alunos que buscam alternativas para minimizar as dificuldades inerentes ao seu

processo de ensino e aprendizagem. É possível observar que muitas vezes esse processo apresenta-se descontextualizado, sendo o aluno um mero expectador. A maneira como os conteúdos matemáticos são apresentados e explorados, por exemplo, acabam por não articular objetivos de ensino que auxiliem a inserção social dos alunos, o desenvolvimento de seu potencial, de sua expressão e interação com o meio.

Ao que diz respeito aos conhecimentos matemáticos dos números naturais especificamente, percebemos que ainda existem diversos problemas que precisam ser superados para que o aluno possa ter um aprendizado satisfatório, impasses estes que se perlongam durante anos, podendo ser caracterizado como obstáculo matemático, visto que os professores utilizam de uma abordagem formalista, não valorizando a parte histórica e social, no qual os alunos estão inseridos, o que acarreta em um ensino desanimador e desinteressante, não despertando a curiosidade e prazer dos mesmos para com o estudo (Martins, Farias \& Rezende, 2015; Moura \& Lopes, 2007; Araujo, et al., 2007).

Como nos dias atuais vivemos em um mundo rodeado pela tecnologia, onde a internet e as Tecnologias de Informação e Comunicação (TIC) possuem papel fundamental de transformação no processo de ensino aprendizagem. Para Richit (2010, p.94), “é possível perceber que com o avanço das (TIC) no ambiente educacional inúmeras mudanças ocorreram, principalmente no que diz respeito à forma como o conhecimento é produzido e internalizado".

À vista disso, entendemos que trabalhar com a tecnologia como recurso didático é uma atividade ascendente, que originam em aulas provocadoras de curiosidades e interesses dos alunos aos estudos, tendo em vista, que estes já possuem contato com a tecnologia em seu cotidiano, onde consequentemente, o uso adequado desta ferramenta resulta no favorecimento de uma aprendizagem significa que permite a relação entre o conhecimento prévio e o novo do aluno nos termos de Ausubel (1982).

No entanto, vale ressaltar que os softwares educacionais não são capazes de esclarecer concepções, identificar e/ou relacionar conceitos, uma vez que isto quem faz é o próprio usuário, portanto, para que isto exista, precisa haver uma conscientização do 
manuseio destes instrumentos com a orientação dos professores, pois, desta maneira será possível a construção da aprendizagem significativa (Brasil, 2016; Gonçalves, 2007).

Logo, com o propósito de contribuir com o processo de ensino e aprendizagem dos números naturais, o presente trabalho utilizou às (TIC) que contribuem na construção de conceitos e conhecimentos matemáticos das operações do conjunto dos números naturais, em um ambiente de aprendizagem fomentador, para conseguir atingir uma relação estreita entre os alunos, professores e a disciplina, de forma dinâmica.

Para tanto, os dados da presente pesquisa foram coletados em uma escola da rede de ensino público do município de Abaetetuba - PA, com público alvo de 33 alunos do " 6 " ano E" do turno da manhã da escola municipal "Cristo Redentor". A metodologia foi balizada pela Engenharia Didática, onde por meio dos expostos apresentados, objetivamos investigar a potencialidade do uso de uma sequência didática para o ensino das quatro operações do conjunto dos números naturais, utilizando a plataforma do APP Inventor 2, para que o processo de ensino e aprendizagem por meio do uso do software operações com números naturais seja motivador, dinâmico e facilitador.

Dessa forma, dividimos o nosso trabalho três partes. Na primeira, é apresentada o referencial para mostrar a importância do uso das (TIC) para educação e o processo de ensino e aprendizagem do das quatro operações com o conjunto dos números naturais. Na segunda parte, o detalhamento das atividades desenvolvidas, os resultados e discussões encontrados. E por fim, as considerações dos objetivos propostos.

\section{A importância do uso das (TIC) no processo de ensino e aprendizagem da matemática}

O uso da tecnologia na educação brasileira surgiu a partir de atividades de pesquisas realizadas na década de 70 nas UFs do país (UFRJ, UFRGS E UNICAMP). Dez anos depois, em meados dos anos 80, o uso delas se implementou por meio de vários exercícios que possibilitou que este campo educacional se consolidasse até nos dias atuais, se tornando uma área de pesquisa e ensino que possui grande influência e relativa maturidade (Valente \& Almeida, 1997).

Com os avanços trazidos por essa ferramenta, o governo brasileiro e as instituições de ensino incluíram esse recurso no seu processo de ensino aprendizagem. Diante disso, entendemos que não haverá progresso em um país sem que sua população seja evoluída e educada tecnologicamente, portanto, para que isso aconteça, seria importante a presença de 
uma educação que possa atender as exigências e desafios do século XXI (Sampaio, Oliveira \& Nespoli, 2005).

Para Miranda e Camossa (2009), o uso da tecnologia dentro de um ambiente escolar, deve ocorrer unido com a população, preenchendo as carências de cada contexto e de cada discente em particular, conseguindo assim, uma perspectiva pedagógica que traga significados notórios para a comunidade, ou seja, é necessário que seja uma ferramenta para auxiliar o processo de aprendizagem dos conteúdos, sendo manuseado também no cotidiano.

Segundo a Base Nacional Comum Curricular - BNCC (2017), define que o currículo dos níveis fundamental e médio deve ter uma base nacional comum complementada, em cada estado e em cada escola, com uma grade diversificada compatível com as características regionais e locais, desse modo, os usos das (TIC) dentro das salas de aulas devem suceder estas conjecturas, assumindo um papel indispensável,

[...] pois funciona como agente de propagação de conhecimento, colocando-se a serviço da educação. Ela funciona como um meio didático, na medida em que pode oferecer representação específica de um saber, facilidades de manuseio, feedback e uma possibilidade para acompanhar, a distância, a construção de um procedimento realizado pelo aluno, observando suas incertezas, hesitações, até que ele encontre o seu caminho (Borges neto, 1998, p. 06).

Isso deixa nítido a importância do uso das (TIC) dentro de sala para o aprendizado do aluno, todavia, o Censo Escolar da Educação Básica 2016, realizado pelo Instituto Nacional de Estudos e Pesquisas Educacionais Anísio Teixeira (INEP) publicado em fevereiro de 2017 mostra que de todas as escolas que oferecem os anos iniciais do ENSINO FUNDAMENTAL, apenas 44,7\% dessas instituições contam com laboratórios de informática. As que ofertam os anos finais do ENSINO FUNDAMENTAL os números de laboratórios disponíveis são de 67,8\%. Os números mais otimistas, segundo a pesquisa, são os das escolas de ensino médio, as quais cerca de $82,7 \%$ utilizam desse recurso.

Em todos os casos os resultados não são satisfatórios, visto que, a educação tecnológica é fundamental para que nossos alunos possam se interessar pela construção do conhecimento. Com isso:

[...] a responsabilidade das escolas e de seus gestores no encaminhamento da questão da informática na educação é indelegável e premente [...] A articulação e o gerenciamento desse processo deve promover os recursos materiais necessários e a formação e capacitação dos recursos humanos, para que ocorra efetivamente uma educação informatizada que atenda aos interesses de uma sociedade que busca o desenvolvimento e que precisa se preparar para assumir o seu espaço como cidadã do mundo (Sampaio, Oliveira \& Nespoli, 2005, p. 125). 
Dessa forma, o desenvolvimento de práticas docente com o auxílio de tecnologia cresce cada vez mais com a sociedade atual. Os sujeitos envolvidos no processo de ensino e aprendizagem do aluno, devem compreender a necessidade da inserção das (TIC), como os softwares educacionais, onde sua implantação precisa ocorrer de maneira espontânea, para não ocasionar obstáculos epistemológicos nos estudantes, especialmente o educando de nível fundamental, no instante que eles começam a manusear os dispositivos tecnológicos.

Borba e Penteado (2010) ressaltam que esses tipos de recursos tecnológicos não devem funcionar como meros recursos didáticos, e sim mostrar seu verdadeiro papel que é de suma importância, onde os alunos e o professor farão parte do processo de ensino. Fazendo com que o conhecimento seja gerado pela interação em um coletivo, envolvendo todos no processo.

Caso contrário, se esse recurso não for trabalhado de maneira correta, o potencial dele poderá ser associado a forma tradicional de se ensinar. Nesse sentido concordamos com Borba e Penteado (2010), pois o professor poderá utilizar todas as potencialidades da tecnologia digital na Educação, como o visual, a manipulação que é atribuída a essa ferramenta pela sociedade no contexto geral.

Nesse contexto, o ensino e aprendizagem por meio dos softwares educacionais devem estar acessíveis a todos os envolvidos de forma direta ou indireta do desenvolvimento cognitivo do discente, para que a utilização dele possa possibilitar “[...] ao aluno, autoconfiança para criar e resolver situações, desenvolvendo autonomia para resolver problemas posteriormente" (Grzesiuk, 2008, p. 23), uma vez que, a introdução da tecnologia em sala de aula, só trará o benefício esperado se a mesma auxiliar a melhoria do ensino.

Dessa forma, o estudo da matemática não deve ser ministrado como um saber estático, pois, essa disciplina está em constante crescimento e reformulação de suas teorias, não devendo forma alguma ser retratada como uma ciência inalterável, abstrata ou sem relação com a realidade do indivíduo.

\section{As quatro operações e seu processo de ensino e aprendizagem}

O ensino e aprendizagem de matemática pode ser compreendido por um triângulo, onde seus vértices são o saber matemático, o aluno e o docente. E os seus lados, compreendem as relações entre eles, aluno e saber matemático, professor e saber matemático, e a relação pedagógica entre professor e aluno. 
Consequentemente, para entender e aprender a matemática, é imprescindível que haja um vínculo de relações, troca de ideias e conhecimentos, de formação contínua para que exista a aquisição de novos saberes, e é evidente que este elo é intermediado pelas orientações dadas pelo professor no ambiente de ensino (Brasil, 1997).

Silva (2014) aponta, que no ensino dos números naturais, procura - se listar às quatro operações e seus conceitos, para em seguida entender como os alunos se posicionam e associam o vínculo do ensino com a aprendizagem, sendo uma ligação que deve ser praticada com toda cautela para que não ocorra alguns "equívocos" cometidos nas escolas, a do aluno ser aprovado para a série/ano seguinte sem saber os algoritmos das operações básicas.

Para realizar atividades com às quatro operações dentro de sala, é de grande valia que o professor busque diretrizes didáticas que o ajude na hora que for realizar a prática metodológica escolhida, que auxilie a estimular as competências necessárias que a disciplina exige, visto que, o ambiente escolar proporciona diversas ocasiões favoráveis para o docente produzir relações integradas de coletas de dados com o ensino da adição, subtração, multiplicação e divisão (Brasil, 2007).

Além disso, e ampliando a fora mencionado acima, Base Nacional Comum Curricular - BNCC, ressalta em suas habilidades que por meio das quatro operações, o aluno deverá "resolver e elaborar problemas que envolvam cálculos (mentais ou escritos, exatos ou aproximados) com números naturais, por meio de estratégias variadas, com compreensão dos processos neles envolvidos com e sem uso de calculadora” (Brasil, 2017, p. 265).

De acordo com Mandarino e Belfort (2005), a aprendizagem do algoritmo da adição e subtração é indispensável, pois, ampara grande parte de aprendizados posteriores dos conteúdos matemáticos. É recomendado que o aluno viva as experiências que contenham o conceito de adição e subtração, para assim, poder transpassar seus conhecimentos para a aprendizagem do algoritmo.

Já no estudo da multiplicação e divisão, de acordo com os Parâmetros Curriculares Nacionais - PCN, os conceitos dessas operações com os números naturais devem ser explorados de maneira conjunta, pois suas relações são bastante aproximadas. Contudo, os PCN, também explicam, que o repasse de suas teorias e propriedades necessitam de um estudo mais aprofundado e amplo, uma vez que, seu processo de ensino e aprendizagem são mais complexos.

Estudiosos como Nascimento (2014), Silva (2014), Soares e Machado (2016), 
apontam que as operações básicas com os números naturais: adição, subtração, multiplicação e divisão, têm sido objetos permanentes de pesquisas para que encontre metodologias diferenciadas que auxiliem os alunos na compreensão e na aprendizagem desses algoritmos, tendo em vista que os alunos completam o Ensino Fundamental Anos Finais sem o domínio necessário destas operações.

Brandt e Bassoi (2016), expressam que para se analisar um erro, o professor deve percebe se o aluno possui o entendimento das teorias que abordam essas operações, como, entender que os numerais submetidos ao cálculo aditivo, por exemplo, causam preposições que podem ser executadas de uma vez, como a contagem de unidades em grupos, necessitando, neste contexto, que o educando consiga desenvolver a lógica da contagem e a cardinalidade de um conjunto, uma vez que essas teorias são de extrema importância para o sucesso das resoluções nas operações matemáticas.

Portanto, a evolução da análise da área da didática matemática apresenta novos rumos para a abordagem das operações, contudo deve ser efetuada de maneira que o aluno consiga entender os diferentes significados dos procedimentos de conclusão de um cálculo, uma vez que, as estruturações destes conceitos levam tempo, sendo ocasionados de maneira natural com o estudo em sala (Brasil, 1997).

\section{O detalhamento da pesquisa}

Esta pesquisa foi balizada nos passos da Engenharia Didática, por ser uma metodologia relacionada inicialmente com o ato de analisar, visando a construção de sequências e materiais didáticos para uma área específica. Os dados foram coletados no período de outubro a dezembro de 2018 Escola Estadual de Ensino Fundamental e Médio Cristo Redentor, localizada no município Abaetetuba - PA, em uma turma do $6^{\circ}$ ano do ensino fundamental com um total de 33 alunos.

Nesse contexto, para todo o material que possui especificidades que possibilitam a descoberta de diversos aspectos de uma teoria matemática, resultando na mudança da relação do indivíduo que possui dificuldades com o objeto matemático em estudo e que auxilia na concepção do conhecimento do sujeito, esta teoria educacional pode ou não ser aplicada em ambientes tecnológicos (Almouloud \& Coutinho, 2008).

Com este método de estudo/pesquisa, Almouloud e Silva (2012) descrevem a engenharia didática possui quatro passos essenciais, que norteiam o seu esquema de 
experimentação: o primeiro fala sobre sua construção inicial, ou seja, a concepção do esquema onde se pretende aplicar, o segundo, a consumação da atividade, o terceiro, fala sobre a observação e o último são as análises da sucessão de ensino. Esta última etapa, nos viabiliza o enfrentamento entre os dados coletados a priori e posteriori à aplicação do projeto, para assim, fazermos ou não a validação do trabalho de pesquisa.

Segundo Almouloud e Silva (2012) uma pesquisa que segue os conceitos de uma engenharia didática, é obrigatória que se passe pelas fases anteriormente evidenciadas, os autores dizem ainda, que cada fase possui características próprias:

1. Análises preliminares: considerações sobre o quadro teórico didático geral e os conhecimentos já adquiridos sobre o assunto em questão, incluem a análise epistemológica do ensino atual e seus efeitos, das concepções dos alunos, dificuldades e obstáculos, e análise do campo das restrições e exigências no qual vai se situar a efetiva realização didática.

2. Concepção e análise a priori das situações didáticas: o pesquisador, orientado pelas análises preliminares, delimita certo número de variáveis pertinentes ao sistema sobre os quais o ensino pode atuar, chamadas de variáveis de comando (micro didáticas ou macro didáticas) [...]

3. Experimentação: consiste na aplicação da sequência didática, tendo como pressupostos apresentar os objetivos e condições da realização da pesquisa, estabelecer o contrato didático e registrar as observações feitas durante a experimentação.

4. Análise a posteriori e validação: A análise a posteriori consiste em uma análise de um conjunto de dados colhidos ao longo da experimentação, como por exemplo, produção dos alunos, registros de observadores e registro em vídeo. Nessa análise, se faz necessário sua confrontação com a análise a priori para que seja feita a validação ou não das hipóteses formuladas na investigação.

Ou seja, a Engenharia Didática segundo Almouloud e Silva (2012), é estruturada simultaneamente com a investigação, a qual os resultados, servirão como instrumentos para a produção de objetos de ensino.

Logo, buscamos investigar a potencialidade dessa ferramenta metodológica que pudesse motivar e estimular na construção dos conhecimentos referentes as operações com os números naturais, dessa forma utilizamos a tecnologia empregada no website MIT App Inventor 2. Para tal, dividimos a nossa proposta em 3 etapas:

Na primeira, unimos as duas primeiras fases da Engenharia Didática proposta por Almouloud e Silva (2012) onde primeiramente, analisamos a maneira que se era trabalhado habitualmente o conteúdo, pois assim poderíamos apresentar uma intervenção que contribuísse na melhoria das dificuldades e obstáculos do aprender apresentados por esses alunos.

Sendo assim, fizemos a aplicação de um questionário (Quadro 1), baseado nas observações, os quais continha duas questões, em ambas foram divididas em letra a, b, c e 
d, com isso, cada letra trabalhava uma operação, na primeira questão era para ser realizados cálculos sem o uso de contexto, já na segunda, as questões continham contextos relacionados a realidade dos alunos.

Quadro 1: Apostila base para o questionário a priori

\begin{tabular}{|c|c|c|c|}
\hline \multicolumn{4}{|c|}{ Questão 01 - Resolva as operações: } \\
\hline a) $281+69$ & b) $95-13$ & c) $200 / 10$ & d) 6 \\
\hline \multicolumn{4}{|c|}{ Questão 02 - Resolva as seguintes situações problemas: } \\
\hline \multicolumn{4}{|c|}{$\begin{array}{l}\text { A professora Larisse foi à feira e comprou meia dúzia de banana e } 3 \text { (três) unidade de maçã para } \\
\text { fazer uma vitamina em sua casa. Quantas unidades de fruta a professora comprou no total? }\end{array}$} \\
\hline \multicolumn{4}{|c|}{$\begin{array}{l}\text { Todos os dias o professor Valdinei possui em sua carteira } \mathrm{R} \$: 20,00 \text { (vinte reais) para quando } \\
\text { sair da escola comprar açaí e levar para sua casa para o almoço. Assim que o professor sai da } \\
\text { escola cristo redentor, para em um comerciante e compra } 3 \text { (três) litros de açaí no valor de } \mathrm{R} \$ \text { : } \\
\text { 4,00. Sabendo que três litros de açaí soma um total de } \mathrm{R} \$: 12,00 \text {, quanto em reais o professor } \\
\text { Valdinei recebe de troco ao comprar o açaí? }\end{array}$} \\
\hline \multicolumn{4}{|c|}{$\begin{array}{l}\text { No problema "a" a professora Larisse comprou meia dúzia de banana e } 3 \text { (três) unidades de } \\
\text { maçã para fazer sua vitamina. Quando a professora chega em casa ela divide as unidades de } \\
\text { frutas para conseguir fazer uma vitamina gostosa e homogenia. A professora percebe, que se } \\
\text { ela dividir a quantidade de banana pela quantidade de maçã, ela consegue a mistura exata para } \\
\text { fazer sua vitamina. Se meia dúzia são } 6 \text { (seis) unidades de banana, e a professora possui } 3 \text { (três) } \\
\text { unidades de maçã, qual o resultado de } 6 \text { (seis) dividido para } 3 \text { (três)? }\end{array}$} \\
\hline \multicolumn{4}{|c|}{$\begin{array}{l}\text { O litro do açaí na cidade de Abaetetuba/PA, custa em média } \mathrm{R} \$: 3,00 \text { à } \mathrm{R} \$: 4,00 \text { (três a quatro } \\
\text { reais), se o professor Valdinei resolve comprar } 3 \text { (três) litros de } \mathrm{R} \$: 4,00 \text { (quatro reais), quanto } \\
\text { em reais o professor Valdinei gastará? }\end{array}$} \\
\hline
\end{tabular}

Fonte: Acervo da pesquisa (2018)

Esses questionários foram resolvidos pelos alunos (Figura 1) sem a intervenção dos autores, com o intuito de coletar dados dos conhecimentos que os alunos possuíam sobre as operações matemáticas (Figura 2).

Figura 1: Aplicação do questionário a priori.

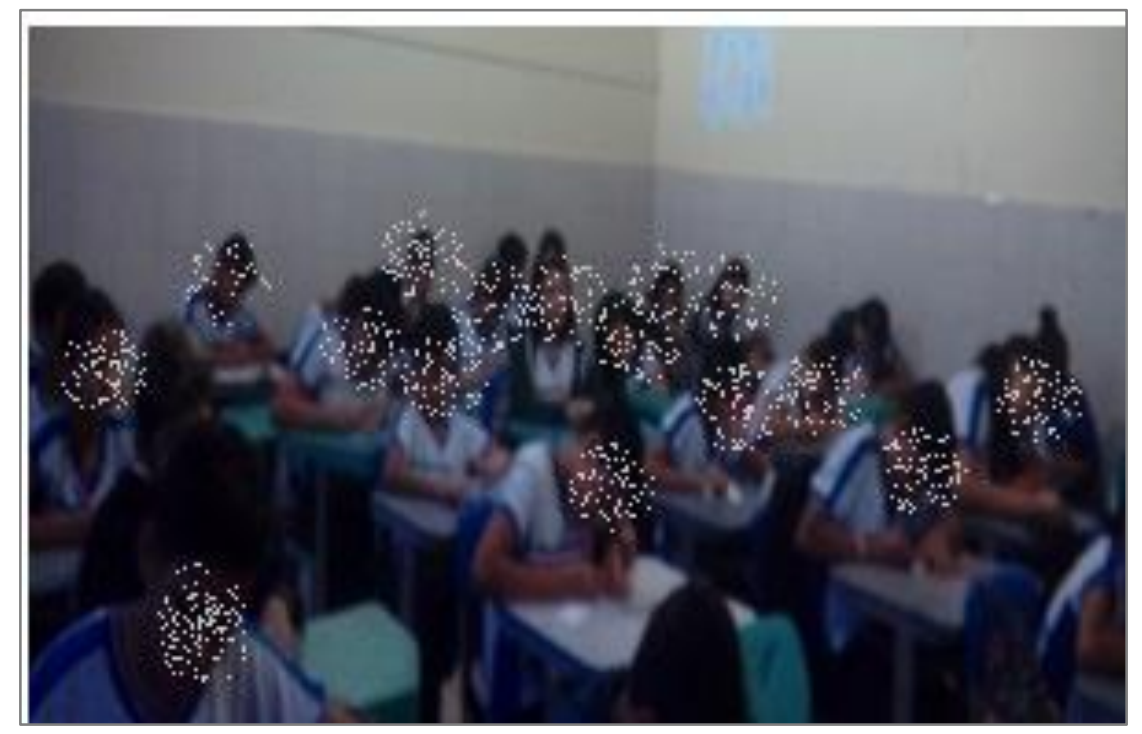

Fonte: Acervo da pesquisa (2018)

Figura 2: Respostas do questionário a priori 


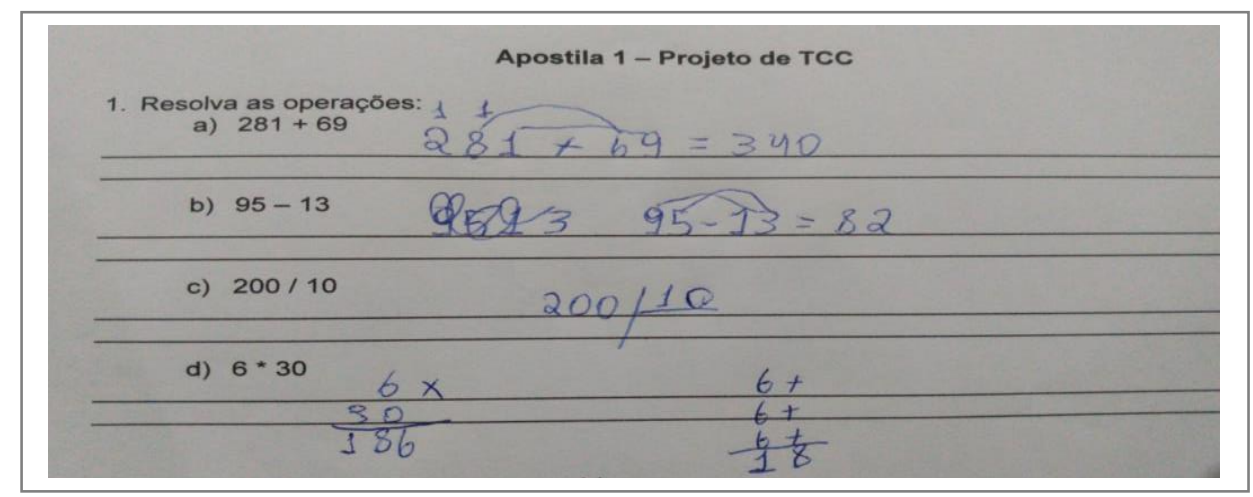

Fonte: Acervo da pesquisa (2018)

Após as análises realizadas pensamos na organização do ensino, são elas:

1. Introduzir e reconhecer o estudo referente as operações básicas (adição, subtração, multiplicação e divisão);

2. Operar os algoritmos das operações básicas;

3. Utilizar as (TIC), em especial os computadores e softwares educacionais, como o App Inventor 2, por ser uma ferramenta acessível e fácil manuseio;

4. Unir a programação e o papel, para resolver questões propostas, tendo como referencial as definições formais.

Feita a organização, partimos para a terceira fase, a experimentação, nela utilizamos 10 encontros, onde começamos pela apresentação de um slide (Figura 3) para explicar aos alunos os passos que seriam seguidos durante a aplicação do projeto, ministramos um micro aula sobre as operações dos números naturais e suas definições. Este momento, teve como objetivo fornecer aos alunos o arcabouço necessário para montar a parte lógica do aplicativo.

Figura 3: Aplicação da micro aula

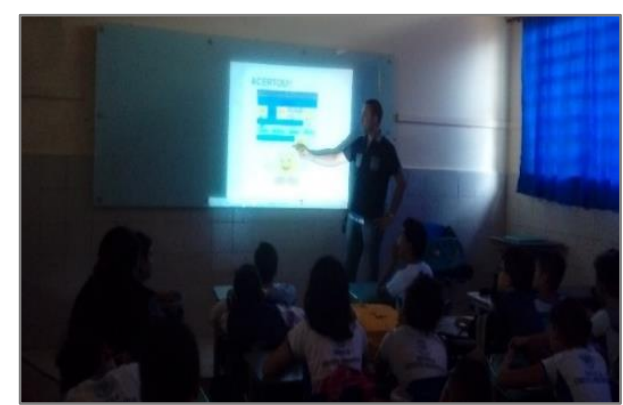

Fonte: Acervo da pesquisa (2018)

Em segunda, iniciamos as sequências de aulas ministradas no laboratório de informática com os grupos de alunos, para cada computador ficaram 2 alunos, e como o laboratório possuía apenas 5 computadores, trabalhamos em grupos de 10 alunos por vez e 
os 3 que restaram ficaram um por vez no computador pessoal, ou seja, a turma foi dividida em três grupos de 11 alunos, conforme está ilustrado na Figura 4.

Figura 4: Aulas no laboratório

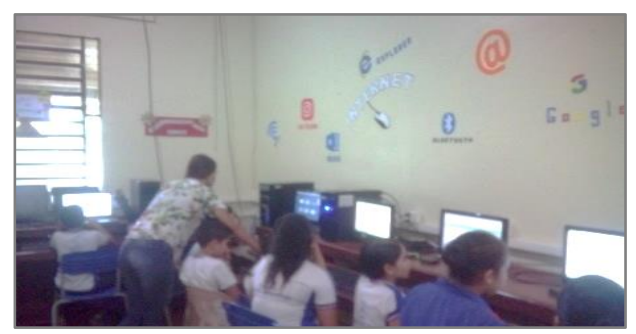

Fonte: Acervo da pesquisa (2018)

Por fim, começamos a contrução do App, utilizando a plataforma App Inventor 2,

desta forma, esse aplicativo é:

Uma linguagem visual de programação para a criação de aplicativos para dispositivos móveis baseados em Android, desenvolvida conjuntamente pelo Google e MIT.O App Inventor possui um ambiente de desenvolvimento baseado em blocos, entretanto, seu diferencial consiste em possibilitar aos usuários criar aplicações que incorporem serviços baseados na web, interação com redes sociais, leitura de códigos de barra, interação com sensores de orientação e geolocalização, e de funcionalidades como text-to-speech e reconhecimento de fala [MIT 2012]. Inspirado nas linguagens Logo e Scratch, o App Inventor propicia um ambiente de aprendizagem baseado no construcionismo, uma vez que permite aos estudantes criarem aplicações à medida que descobrem e exercitam sua criatividade, tornando o aprendizado mais lúdico. A criação de aplicativos com o App Inventor é bastante intuitiva e não exige conhecimento prévio avançado em programação. Além disso, os aplicativos criados podem ser utilizados em quaisquer dispositivos com a plataforma Android (GOMES; MELO, 2003, p.62).

\section{A construção do Aplicativo Operações com Números Naturais - App - ONN}

As sequências de aulas montadas para a construção do aplicativo na plataforma do APP Inventor 2, foi alicerçada de acordo com as dificuldades encontradas, a quantidade de horários de aula e as atividades realizadas estão descritas nos Quadros 2 e 3.

Quadro 2: Esquema de elaboração do design e do sistema de programação da operação soma e subtração

\begin{tabular}{|c|c|}
\hline \multicolumn{2}{|c|}{ Operações de Adição e Subtração } \\
\hline Quantidades de horários & Atividade realizada \\
\hline 2 & Montar o design das operações \\
\hline 8 & Montar os blocos das operações \\
\hline
\end{tabular}

Fonte: Acervo da pesquisa (2018)

Quadro 3: Esquema de elaboração do design e do sistema de programação da operação multiplicação e divisão

\begin{tabular}{|c|c|}
\hline \multicolumn{2}{|c|}{ Operações de Multiplicação e Divisão } \\
\hline Quantidades de horários & Atividade realizada \\
\hline 3 & Montar o design das operações \\
\hline 10 & Montar os blocos das operações \\
\hline
\end{tabular}

Fonte: Acervo da pesquisa (2018) 
Isto é, para montarmos a face de cada operação matemática na plataforma do APP Inventor 2, utilizamos um total de 5 horários de aula e para elaboração dos blocos, que diz respeito ao sistema de programação do aplicativo, fizemos uso de 18 horários de aula.

O sistema de programação do aplicativo, o qual corresponde aos blocos montados, possuem 4 telas distintas, uma para adição, subtração, multiplicação e divisão e temos 4 botões que necessitam de uma lógica específica, os botões apagar e fechar são os mais simplórios, pois suas funções são zerar as caixas de textos e voltar para a tela anterior respectivamente.

A seguir iremos mostrar a programação realizada e suas contribuições no processo de ensino das operações.

O botão iniciar das operações adição e multiplicação possuem a mesma lógica de programação, visto que, suas nomenclaturas não precisam de ordem numérica, ou seja, os valores das parcelas e dos fatores, podem possuir um valor menor seguido de um maior, ou vice e versa, não interferindo no resultado. Já que estamos trabalhando apenas com números não negativos, estas características são evidenciadas nos blocos de cores azuis, o qual também, é responsável pelo grau de dificuldade.

Figura 5: Sistema de programação do botão iniciar da tela adição

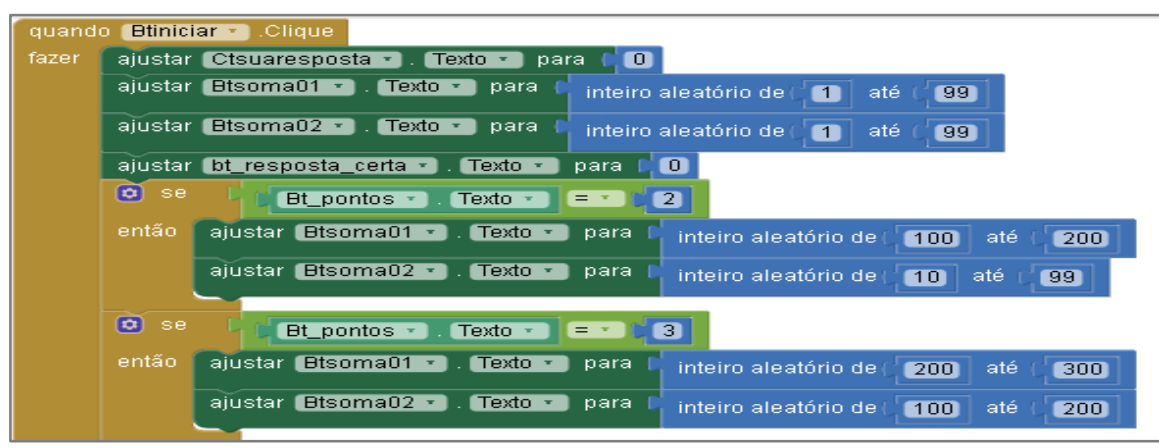

Fonte: Acervo da pesquisa (2018)

O sistema de programação do botão iniciar da operação de subtração, mostra algumas especificidades, pois, o minuendo, deve, obrigatoriamente, ser maior em quantidade, que o número do subtraendo, para assim, obtermos um resultado com um número positivo, já que estamos trabalhando apenas com os números positivos. Esta lógica, também é vista nas peças de cores azuis, sendo responsáveis pela elevação do grau de dificuldade de cada cálculo.

Observando a Figura 6, percebemos a existência do botão "bt_pontos seguido do número 4, ou seja, quando o aluno acumular quatro acertos, o nível do cálculo se eleva entre os números 100 e 999 no minuendo e 10 e 99 no subtraendo, assim continuadamente. 
Figura 6: Sistema de programação do botão iniciar da tela subtração

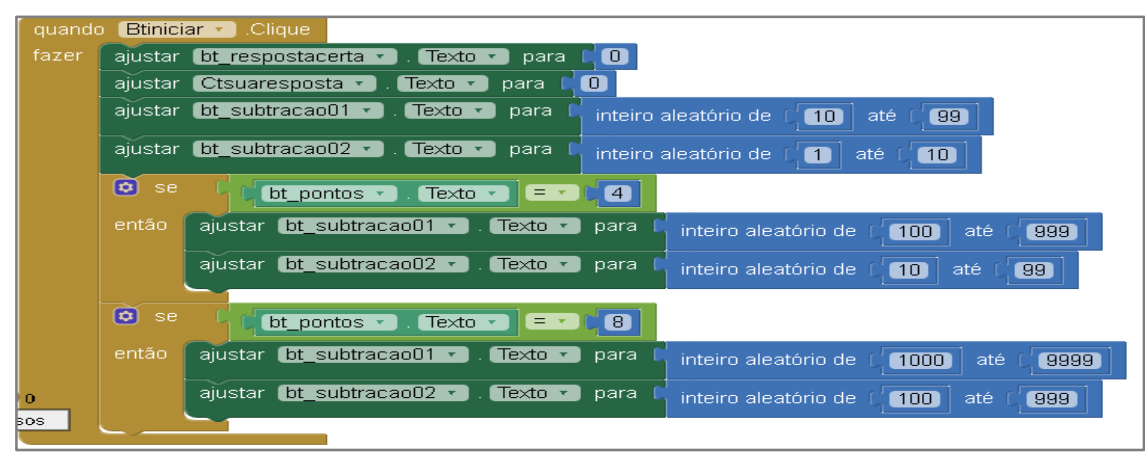

Fonte: Acervo da pesquisa (2018)

A Figura 7, refere - se a programação do botão "iniciar" da operação de divisão, a primeira observação precisa ser nas denominações de cada bloco, visto que, aqueles que se inicia com as letras "Ct", significam que são caixas de textos, aqueles que começam com as letras "bt", apresentam os botões desta operação. Assim, o aluno ao unir os blocos, entende que quando o botão iniciar for acionado as "Ct" irão zerar, mostrando um novo cálculo, simultaneamente a está ação os "bt" exibem um novo cálculo, exceto aqueles que correspondem ao botão do "resto" e da "resposta_certa", pois estes também zeram.

Figura 7: Sistema de programação do botão iniciar da tela divisão

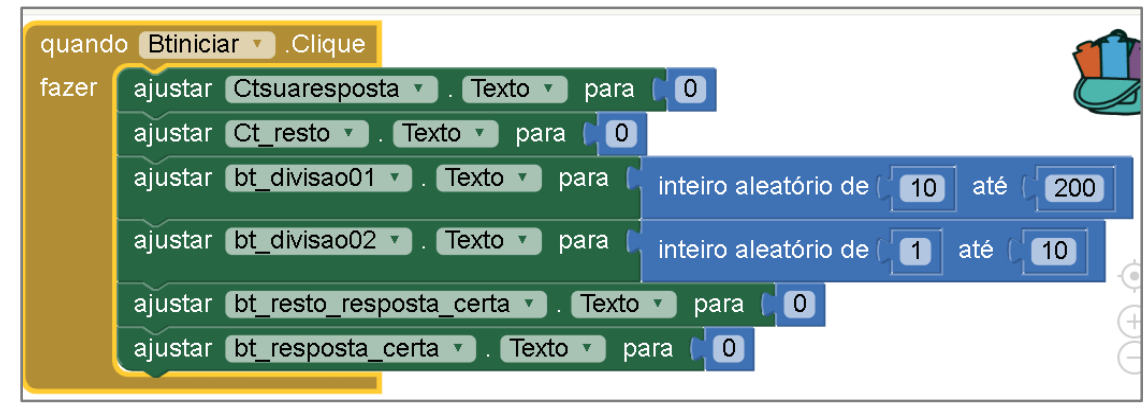

Fonte: Acervo da pesquisa (2018)

Esta lógica, vista na Figura 7, mostra que os blocos de cores azuis fazem referência ao número do dividendo e do divisor, uma vez que, para obtenção de um algoritmo com um resultado exato ou não exato (quando houver resto maior que zero no cálculo), o número do dividendo deve ser maior que o número do divisor, como exemplifica a figura nos blocos que trazem os números 10 e duzentos.

A Figura 8 refere - se a tela do botão apagar da divisão, porém em todos as outras operações, tanto o botão apagar, quanto o fechar não possuem alterações na sua lógica de montagem.

Figura 8: Sistema de programação dos botões apagar e fechar de tela divisão 


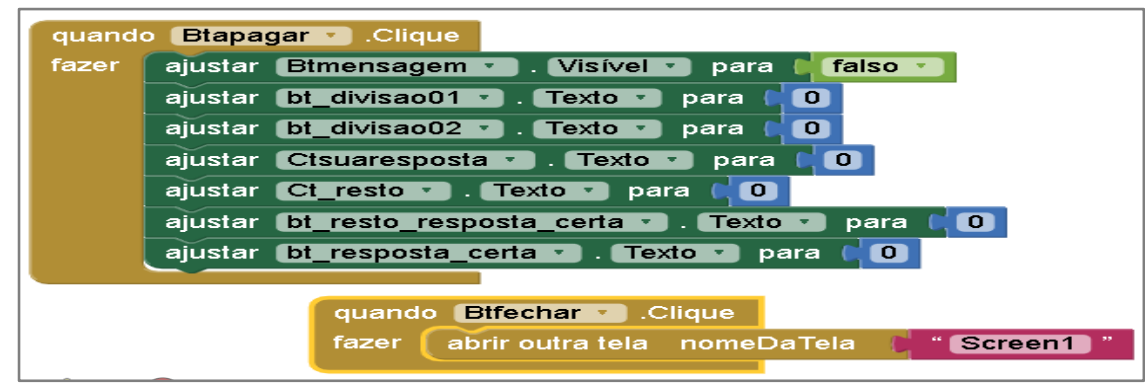

Fonte: Acervo da pesquisa (2018)

Já na Figura 9, a lógica de programação do botão "verificar" da operação adição se assemelha as demais operações, este botão irá validar o resultado, logo, todo o esquema montado nos botões "iniciar", são processados no momento em que o usuário do aplicativo aciona o botão "verificar". Esta lógica é toda montada em função do erro ou do acerto do cálculo, uma vez que, se a resposta colocada não for a correta esta tecla mostrará um emotion que possui um semblante triste seguido de um áudio com o som de errou, caso contrário, aparecerá um emotion com um sorriso, seguido do som de aplausos.

Figura 9: Sistema de programação do botão verificar da tela adição

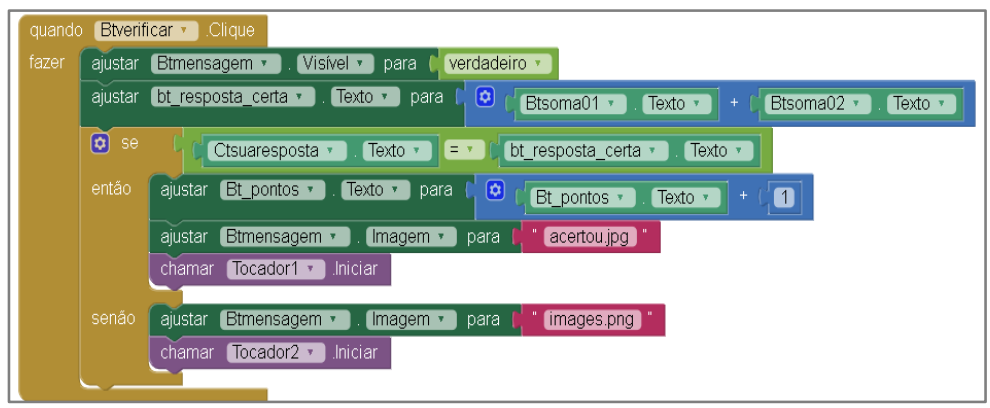

Fonte: Acervo da pesquisa (2018)

Com isso, verificamos que a programação para a construção do aplicativo App ONN, por meio da plataforma do App Inventor 2, contribui no processo de ensino e aprendizado, visto que, ao começar com o botão "iniciar", os alunos ao sobrepor os botões, começaram a entender o conteúdo que estava inserido por meio das montagens dos pequenos blocos, sendo que, este botão é responsável pela iniciação do jogo em si, e a cada resposta certa ou errada, ele precisa ser acionado para que ocorra um novo cálculo.

Além dessas, ressaltamos que com a construção do aplicativo App ONN, os alunos foram se familiarizando com as especificidades relacionadas a cada algoritmo das operações mostradas, como na divisão, que foi explicado por meio da montagens dos blocos, na qual a divisão com os conjunto dos números naturais necessita ser com os números $\{1,2,3,4,5, \ldots\}$.

Após a fase de programação, cada aluno conseguiu chegar no Layout do App - ONN (Figura 10) que é composta por cinco botões, permitindo que o usuário entre em 4 abas 
distintas, sendo cada aba por vez, essas, correspondem as operações do conjunto dos números naturais, conforme visto na figura abaixo, e o último botão, o de "fechar" representa a função de sair do aplicativo.

Figura 10: Tela principal do aplicativo

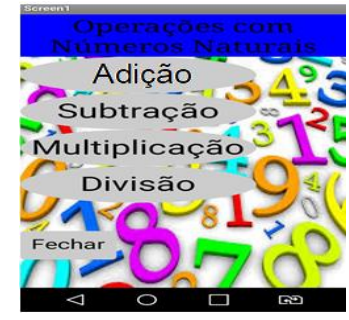

Fonte: Acervo da pesquisa (2018)

A Figuras 11, 12, 13 e 14, corresponde as abas das operaçãoes, perceba que a uma semelhança, as 4 abas, apresentam 3 espaços que correrpondem o número de pontos, o da resposta do aluno e aquele que traz a resposta correta. A única aba que contém mais espaços que estes descritos, é o da Figura 14, a qual equivale ao cálculo da operação divisão.

Figura 11: Tela da Adição

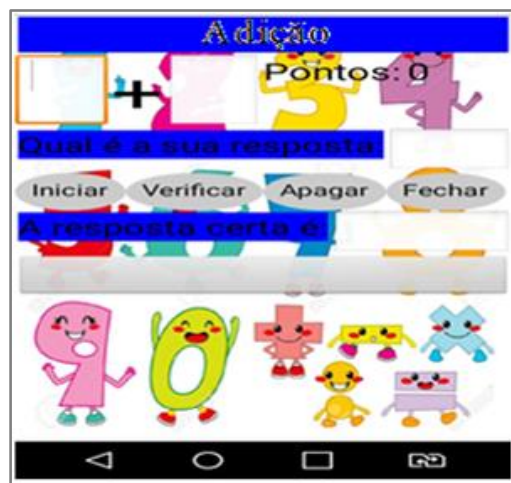

Figura 12: Tela da Subtração

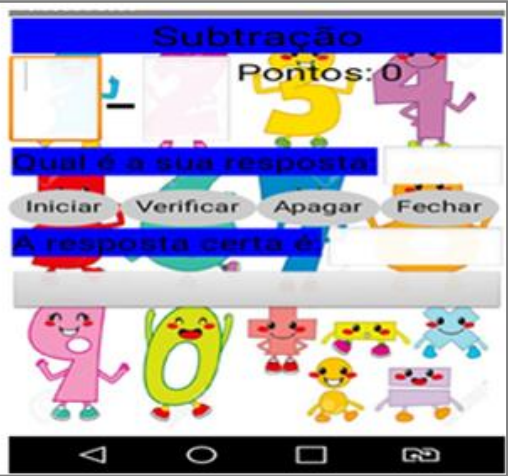

)

Fonte: Acervo da pesquisa (2018)

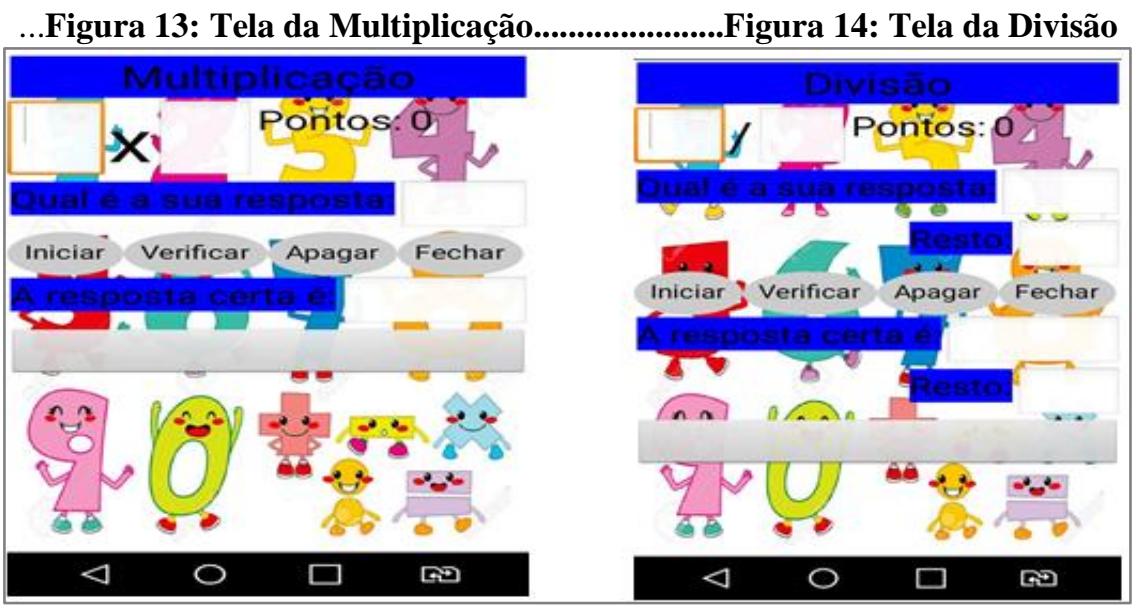

Fonte: Acervo da pesquisa (2018) 
Já nas Figuras 15 e 16, mostraremos que ao abrir do aplicativo, para começar a jogar, o aluno deve apertar o botão "iniciar", e irá aparecer um cálculo para resolver, quando ele souber a resposta o mesmo irá colocar "Qual a sua resposta" e em seguida apertar no botão "verificar" para correção de seu algoritmo. Se sua resposta for correta, aparecerá um emontion com uma carinha sorrindo, seguido de um som de aplausos, se a resposta for incorreta, aparecerá um emotion com uma carinha triste (negação) seguindo de um som que expressa a palavra errou, conforme mostra as figuras abaixo.

Figura 15: Tela do Acerto

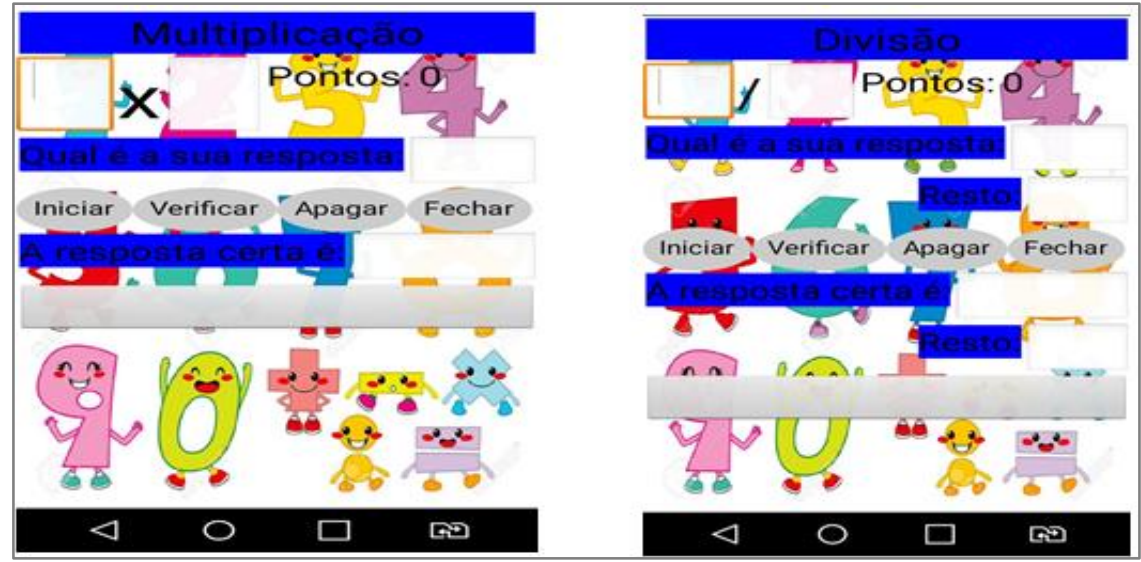

Fonte: Acervo da pesquisa (2018)

Figura 16: Tela do Erro
Portanto, o aplicativo App - ONN, consiste em uma espécie de calculadora com cálculos já preestabelecidos, que ensina os cálculos existentes dentre os conjuntos dos números naturais (adição, subtração, multiplicação e divisão), o intuito de seu uso é motivar o aluno, visto que o mesmo estará utilizando de jogos para aprender um assunto matemático que normalmente é apresentado a ele de maneira tradicional, o seu funcionamento fundamenta - se como auxílio para o ensino dos algoritmos, pois, mesmo com o software em mãos, o aluno necessitará realizar os cálculos por meio de anotações ou mentalmente, a cada cálculo resolvido de maneira correta, o aluno ganha 1 ponto e o grau de dificuldade da conta é elevado.

Após a explicação e montagens de todos os aspectos do aplicativo, levamos os alunos para a sala, para que eles mesmos pudessem manusear o seu trabalho, neste momento, fizemos uma gincana dentro de sala, dividindo os alunos em equipe auxiliando - os nas resoluções dos exercícios propostos pelo aplicativo, e simultaneamente, explicávamos a ligação do que foi ministrado dentro de sala, criado em laboratório, com a prática do uso do aplicativo, posteriormente aplicamos o questionário a posteriori (Quadro 4), como mostra a Figura 17, para analisar se a metodologia utilizada foi ou não satisfatória, todo este processo 
foi realizado em 8 horários.

Quadro 4: Apostila base para o questionário a posteriori

\begin{tabular}{|c|c|c|c|}
\hline \multicolumn{4}{|c|}{ Resolva as operações: } \\
\hline a) & b) $568-159$ & c) $172 / 4$ & \\
\hline \multicolumn{4}{|c|}{ destão 02 - Resolva as seguintes situações problemas: } \\
\hline \multicolumn{4}{|c|}{$\begin{array}{l}\text { a) A diretora Karina iria realizar um sorteio na escola Cristo redentor, para arrecadar fundos } \\
\text { para o dia da festa da escola, ela percebeu que se fosse distribuído uma quantidade X de } \\
\text { cartela para cada aluno, ela conseguira arrecadar a quantia necessária para o festejo. A } \\
\text { turma do } 6^{\circ} \text { Ano E do turno da manhã da escola cristo redentor têm } 33 \text { alunos e a diretora } \\
\text { distribuiu } 5 \text { cartelas para cada um deles. Quantas cartelas no total a turma possui? }\end{array}$} \\
\hline \multicolumn{4}{|c|}{$\begin{array}{l}\text { b) Para comemorar o dia dos professores, a diretora comprou bolo, pão e refrigerante para } \\
\text { realizar uma surpresa para eles durante o intervalo de aula. Sabendo que o refrigerante } \\
\text { custou } \mathrm{R} \$: 5,00 \text {, o bolo, } \mathrm{R} \$: 15,00 \text { e o pão } \mathrm{R} \$: 3,00 \text {. Quanto a diretora gastou no total? }\end{array}$} \\
\hline \multicolumn{4}{|c|}{$\begin{array}{l}\text { c) O Professor Valdinei antes de entrar em sala de aula para começar a explicar a matéria, } \\
\text { foi até a lanchonete da escola cristo redentor e comprou dois lanches completos, os quais } \\
\text { ele pagou R } \$: 6,00 \text {. O professor tinha em sua carteira R } \$: 55,00 \text {, quanto a "tia do lanche" } \\
\text { devolveu para ele de troco? }\end{array}$} \\
\hline \multicolumn{4}{|c|}{$\begin{array}{l}\text { d) O Professor Valdinei antes de entrar em sala de aula para começar a explicar a matéria, } \\
\text { foi até a lanchonete da escola cristo redentor e comprou dois lanches completos, os quais } \\
\text { ele pagou R } \$ \text { : } 6,00 \text {. O professor tinha em sua carteira } R \$: 55,00 \text {, quanto a "tia do lanche" } \\
\text { devolveu para ele de troco? }\end{array}$} \\
\hline
\end{tabular}

Fonte: Acervo da pesquisa (2018)

Após a explicação e montagens de todos os aspectos do aplicativo, os alunos foram para a sala de aula, para que eles mesmos pudessem manusear o seu trabalho, neste momento, fizeram uma atividade onde explicamos a ligação do que foi ministrado dentro de sala e criado no laboratório, posteriormente aplicamos o questionário final para que pudéssemos validar ou não a referida pesquisa.

Figura 17: Respostas do questionário a posteriori

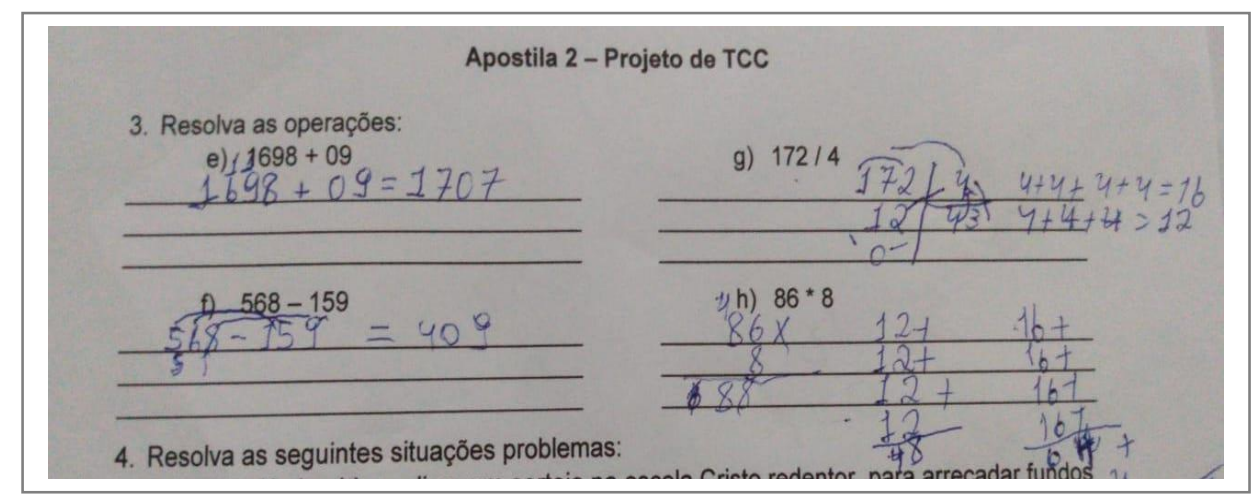

Fonte: Acervo da pesquisa (2018)

\section{Resultados}

A análise dos resultados será apresentada por meio de gráficos, a qual é visto como a quarta e última fase da Engenharia Didática, corresponde a análise a posteriori e validação do diagnóstico adquirido ao longo da aplicação do projeto. Cada gráfico, corresponde a uma 
operação por vez, onde os alunos acertaram ou erraram as alternativas, possibilitando uma análise clara e convicta.

Gráfico 1: Erros e Certos correspondente a operação adição

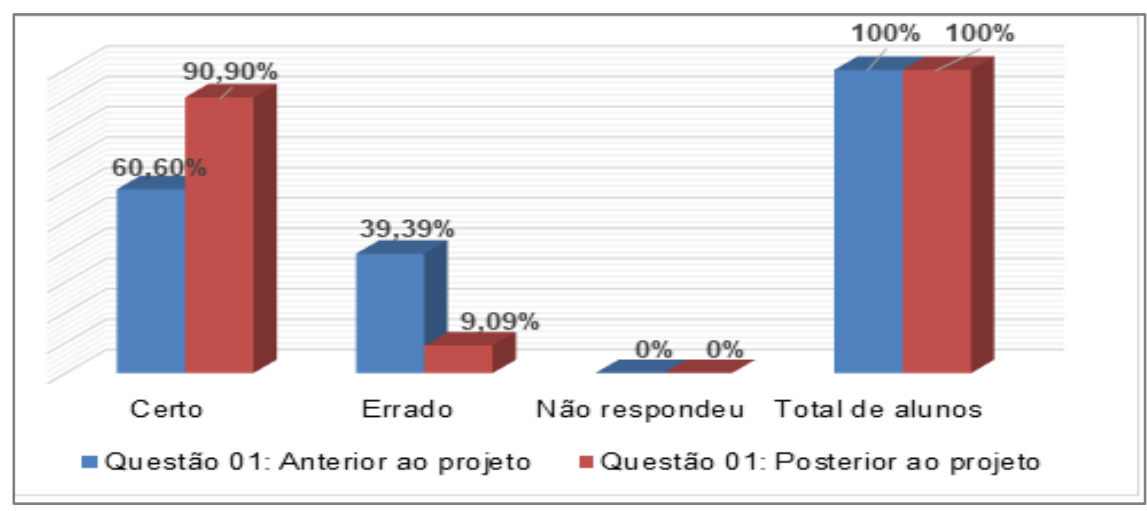

Fonte: Acervo da pesquisa (2018)

O gráfico acima mostra que a porcentagem de acertos após a aplicação do projeto subiu em mais de $30 \%$ na mesma proporção que o número de erros baixou, visto que anteriormente a aplicação estes dados eram de $60,6 \%$ e $39,4 \%$ e posteriormente $90,9 \%$ e $9,1 \%$ respectivamente, como expõe o gráfico acima.

Gráfico 2: Erros e Certos correspondente a operação subtração

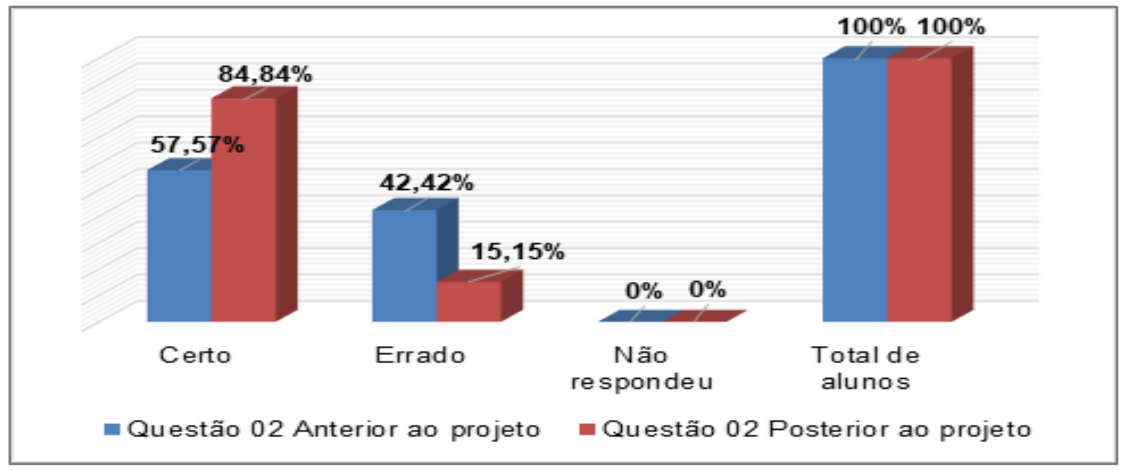

Fonte: Acervo da pesquisa (2018)

Em relação aos dados do segundo gráfico, referentes a operação subtração que anteriormente a nossa intervenção já eram consideráveis aceitáveis, visto que mais de 57\% da turma conseguiu realizar de maneira correta, emergiu ainda mais, realçando que a ferramenta utilizada gerou resultados significativos, já que de 57,57\% o número de acertos subiu para $84,84 \%$ como ilustra o gráfico deste algoritmo. 
Gráfico 3: Erros e Certos correspondente a operação multiplicação

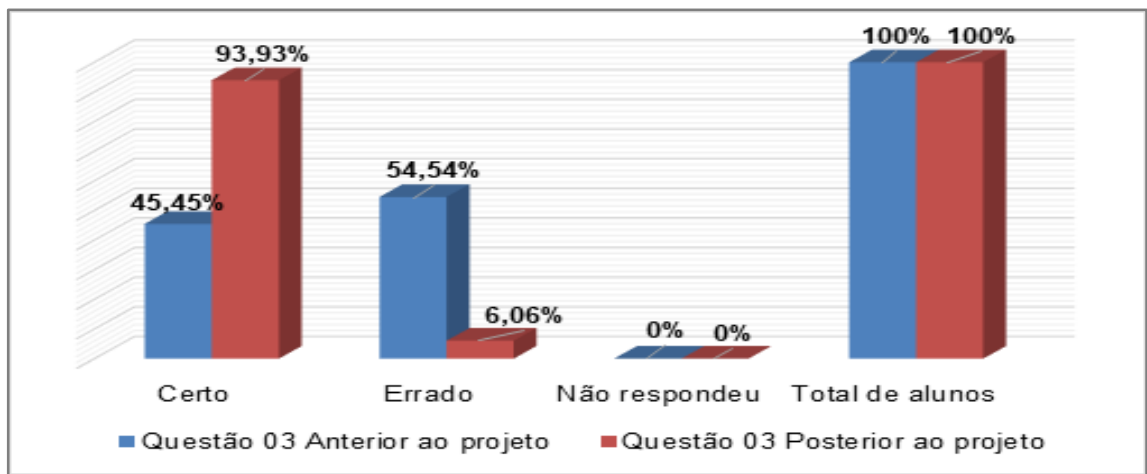

Fonte: Acervo da pesquisa (2018)

Já o terceiro gráfico, exibe o segundo menor porcentual de acertos, quando comparamos os resultados das outras operações, neste algoritmo menos da metade dos educandos conseguiram realizar de forma correta antes da nossa intervenção, contudo, após a aplicação do projeto este número sobe de $45,45 \%$ para $93,9 \%$, evidenciando um excelente desenvolvimento na aprendizagem dos alunos.

Gráfico 4: Erros e Certos correspondente a operação divisão

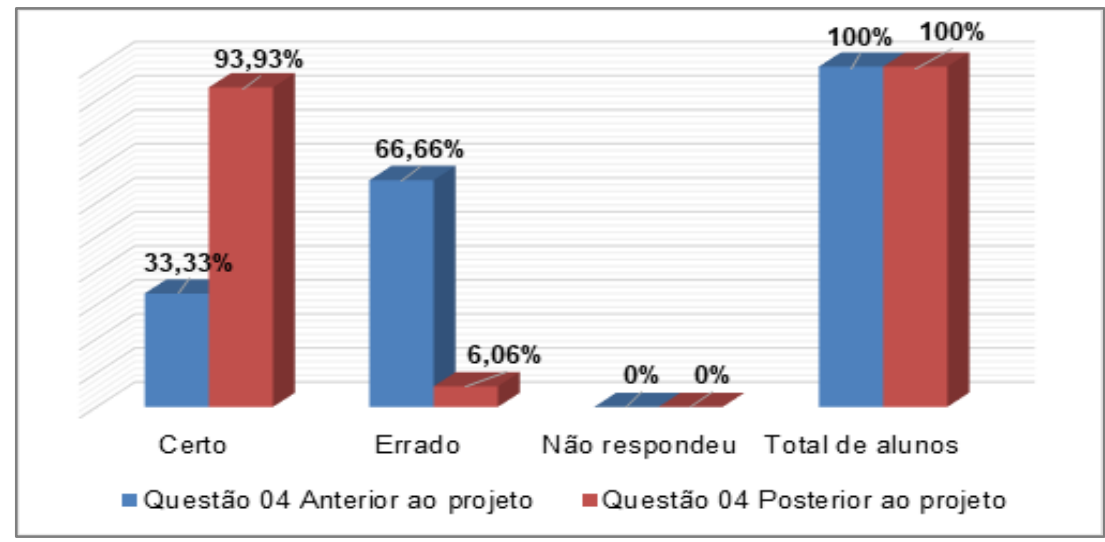

Fonte: acervo da pesquisa (2018)

Por fim, o último gráfico, mostra uma excelente crescente nos acertos, esta evidenciado nos resultados, que posteriori ao projeto o número de conclusões corretas soma um total de $93,9 \%$ e de incorreta $6,7 \%$.

Ao revisar todos os gráficos detalhadamente, o que nos chama a atenção é que o espaço reservado a opção de "não respondeu", em todos os casos estão $0 \%$, ou seja, mesmo que o aluno não soubesse o cálculo, o mesmo tentou resolver. Com isso, certificamos a validação da metodologia com o uso da Engenharia Didática, em razão que as hipóteses efetuadas no objetivo proposto nesta pesquisa foram alcançadas. 


\section{Conclusão}

A pesquisa proporcionou entendimento em relação ao ensino das quatro operações fundamentais a partir de uma metodologia diferenciada, que teve por objetivo investigar a potencialidade do uso de uma sequência didática, utilizando a plataforma do APP Inventor 2, para o ensino das quatro operações do conjunto dos números naturais. $\mathrm{O}$ uso da plataforma nos permitiu desenvolver um processo de ensino e aprendizagem motivador, dinâmico e facilitador.

Nesse sentido, a prática adotada para a execução da proposta de intervenção possui grande significado em relação ao emprego de alternativas informáticas para o ensino de conteúdos matemáticos que diferem do quadro atual de ensino dos alunos, visto que, a cada atividade realizada, era visível o entusiasmo no processo de aprendizagem. Esta alternativa de ensino mostrou - se eficiente e interativa em sala, proporcionando ao professor uma ação mais eficaz nas atividades planejadas.

Este estudou provocou reflexões acerca do ensino de matemática e da necessidade de diferentes abordagens, na tentativa de contribuir com as dificuldades apresentadas por alunos do $6^{\circ}$ ano do Ensino Fundamental no que tange as operações básicas. Percebemos em alguns momentos interação entre os alunos, certa cooperação e compartilhamento de aprendizagens entre eles, o que contribuiu para o alcance do objetivo desejado.

Portanto, introduzir às (TIC), como os softwares educacionais, por meio dessa Sequência Didática é uma alternativa viável, mesmo sendo um desafio que ainda precisa ser superado pelas escolas da educação básica. Essa ferramenta deve ser utilizada como um recurso complementar ou um recurso que venha contribuir na sua prática do professor.

Dessa forma, todos os quatros passos expostos na metodologia deste trabalho, desempenharam papel fundamental na construção dos conceitos das operações básicas, visto que no decorrer das atividades, foi possível identificar o grau de entendimento dos alunos em relação ao conteúdo, com isso, recomendamos o uso desse software, associado a uma sequência didática como método de ensino, visto que, é uma excelente alternativa para o processo de ensino e aprendizagem das quatro operações básicas. 


\section{Referências}

Almouloud, S. A. \& Coutinho, C. de Q. (2008). Engenharia Didática: características e seus usos em trabalhos apresentados no GT-19 / ANPEd ${ }^{1}$. Revista Eletrônica de Educação Matemática. 3(6), 62-77.

Almouloud, S. A., \& da Silva, M. J. F. (2012). Engenharia didática: evolução e diversidade Didactic engineering: evolution and diversity. Revista Eletrônica de Educação Matemática, 7(2), 22-52.

Ausubel, D. P. (1982). A aprendizagem significativa: a teoria de David Ausubel. São Paulo: Moraes.

Brandt, C. F., \& Bassoi, T. S. (2016, 13-16 de julho). As dificuldades dos alunos, do $6^{\circ}$ ano do ensino fundamental, para a realização das operações fundamentais: adição, subtração, multiplicação e divisão com números naturais [ponencia]. Encontro Nacional de Educação Matemática (Educação Matemática na Contemporaneidade: desafios e possibilidades, São Paulo, Brasil.

Borba M. C., \& Penteado, M. G. (2001). Informática e Educação matemática. Belo Horizonte: Autêntica.

NETO, H. B. (1998). Uma Classificação Sobre A Utilização Do Computador Pela Escola [ponencia]. IX Encontro Nacional de Didática e Prática de Ensino - versão reelaborada, São Paulo, Brasil.

Brasil. (1997). Parâmetros curriculares nacionais: Matemática. Secretaria de Educação Fundamental. Brasília, MEC/SEF.

Brasil. (2007). Caderno de teoria e pratica 3: Operações Com Números Naturais. (Programa gestão da aprendizagem escolar gestar I) - Ministério da Educação: Secretaria de Educação Básica. Brasilia.

Brasil. (2017). Base Nacional Comum Curricular. Versão Final. Brasília: Ministério da Educação.. Disponível em: http://basenacionalcomum.mec.gov.br/images/BNCC_EI_EF_110518_versaofinal_site. pdf. Acesso em: 08 de agosto de 2020.

Brasil. (2017). Sendo Escolar da Educação Básica 2016: Notas Estatísticas. Ministério da Educação - Instituto Nacional de Estudos e Pesquisas Educacionais Anísio Teixeira. Brasília - DF.

Grzesiuk, D. F. (2008). O uso da informática na sala de aula como ferramenta de auxilio no processo ensino-aprendizagem. Monográfica de Especialização em Métodos e Técnicas de Ensino, Universidade Tecnológica Federal do Paraná.

Mandarino, M. C., \& Belfort, E. (2005). Números naturais: conteúdo e forma. Ministério da Educação: Universidade Federal do Rio de Janeiro, Laboratório de Pesquisa e Desenvolvimento em Ensino de Matemática e Ciências.

Miranda, R. G., \& Camossa, J. P. (2009). O Uso Da Informática Como Recurso Pedagógico: Um Estudo De Caso. Araras.

Nascimento, L. C., Silva, A. J., \& Silva, S. A. (2010). Dificuldades Com Operações Básicas Com Números.

Richit, A. (2020). Aspectos conceituais e instrumentais do conhecimento da prática do professor de cálculo diferencial e integral no contexto das tecnologias digitais. 
Disponível

em

https://scholar.google.com.br/scholar?q=Andriceli+Richit\&btnG=\&hl=ptBR\&lr=lang \&as_sdt=0\%2C5. Acesso em: 05 mar.

Sampaio, C., Oliveira, L., \& Nespoli, V. A. (2005). Informática no Suporte ao Desenvolvimento do Processo Ensino-Aprendizagem na Educação Básica no Brasil. Revista Brasileira de Estudos Pedagógicos, 86(213/214), 121-141.

Silva, R. W. (2014). O Ensino Aprendizagem Das Quatro Operações Com Números Naturais No $5^{\circ}$ Ano Do Ensino Fundamental: um Estudo da EEMEF "Arnoud Dantas do Nascimento" [Trabalho de Conclusão de Curso, Universidade Estadual da Paraíba].

Valente, J. A., \& De Almeida, F. J. (1997). Visão analítica da informática na educação no Brasil: a questão da formação do professor. Revista Brasileira de Informática na Educação, 1(1), 45-60.

Autores

Larisse Lorrane Monteiro Moraes

Possui graduação em Matemática pela Universidade do Estado do Pará (2019) e especialização em Gestão e Docência do Ensino Superior pela Faculdade de Educação e Tecnologia da Amazonia (2019). Atualmente, é professor de matemática na Escola M. De Ensino Fundamental São Felipe. Tem experiência na área de Matemática. E-mail: larissemoraes.12@gmail.com

Bruno Sebastião Rodrigues da Costa

Pós-graduação Stricto Sensu - Ensino de Docência em Educação em Ciências e Matemática - Universidade Federal do Pará. Pós-graduação Lato Sensu - Educação Matemática - Universidade Federal do Pará (2008). Atua como professor de matemática na Universidade do Estado do Pará - UEPA. Professor Formador da Universidade Aberta Brasil - UAB. Pesquisadora do Grupo de Pesquisa em Matemática e Tecnologia Ensino na linha Metodologia do Ensino de Matemática no Nível Fundamental. E-mail: matbrunocosta@gmail.com

Valdinei Gomes Melo

Possui graduação em Matemática pela Universidade do Estado do Pará (2019). Atualmente, ou professor de matemática em uma rede básica de ensino, não em um município de Igarapé Miri. E-mail: vgmelo2017@gmail.com

Talita Carvalho Silva de Almeida

Doutorado em Educação Matemática (Pontifícia Universidade Católica de São Paulo (2015)). Professor da Universidade Federal do Pará, pertencente ao Instituto de Educação Matemática e Científica (IEMCI). Tem experiência na área de Educação Matemática, com ênfase em Ensino e Aprendizagem de Matemática, Didática de Matemática, Tecnologias e

Meios de Expressão e Uso de Ambientes de Computação para o Ensino de Matemática.

E-mail: talita_almeida@yahoo.com.br 